\title{
La movilidad urbana como modus operandi que edifica las ciudades
}

\section{Urban cities in movement as a modus operandi to built them}

\author{
Duthilleul, Jean-Marie (2012), Circuler: Quand nos \\ mouvements faÇonnent la ville, Editions Alternatives, \\ PARIS, 208 PP., ISBN: 978-2-862-277-27-I.
}

La obra Circuler: quand nos mouvents façonnent la ville es el resultado de una exposición del mismo nombre realizada en la Ciudad de la Arquitectura y del Patrimonio de París entre abril y agosto de 2012. El curador de la exposición fue el arquitecto e ingeniero francés Jean-Marie Duthilleul, relevante por su trabajo en torno a la rehabilitación de las estaciones de trenes en Europa, gracias a su visión sobre los espacios de la movilidad como verdaderos territorios de vida, y no como simples espacios de paso desprovistos de humanidad.

La información que integra el libro es una recopilación de los ejes temáticos tratados en la exposición, en donde especialistas y actores franceses de la movilidad urbana participaron con una serie de artículos y archivos fotográficos, entre ellos: Jean-Pierre Orfeuil, profesor y director del Consejo Científico del Instituto de la Ciudad en Movimiento (ICM); Georges Amar, ex-director de la prospectiva de la Régie Autonome des Transports Parisiens (RATP); Vincent Kaufmann, sociólogo, profesor y especialista de la movilidad urbana; Bruno Marzloff, sociólogo, especialista de la movilidad urbana y director de Human Chronos; Simone Roux, profesora emérita de la Sorbona, especialista de la historia de la sociedad urbana entre los siglos XIV y XV; Bertrand Lemoine ingeniero especialista de la historia de la arquitectura y de la construcción urbana entre los siglos xIX y xx, actual director del Taller Internacional del Gran París. Este laboratorio de autores nos permite comprender la evolución de la movilidad urbana a través de los medios de locomoción y los espacios construidos o adaptados para su circulación.

\section{El movimiento, modus operandi de las ciudades}

Actualmente los desplazamientos físicos y virtuales de personas, mercancías, conocimientos, información, imágenes y sonidos constituyen el movimiento de nuestras ciudades; sin embargo, los desplazamientos están 
asociados con diversos intereses, en efecto, el principal objetivo de la movilidad no reside en el movimiento mismo, sino en el acceso a los recursos del territorio (servicios públicos, comercios, conocimiento). La movilidad se convierte así, en un elemento fundamental para conocer la diversidad del mundo y acceder a sus recursos. Sin posibilidad de circulación, las personas quedan excluidas de participar en la vida colectiva y en el intercambio con el otro. De tal manera, el Instituto por la Ciudad en Movimiento (Institut de la Ville en Mouvement) plantea la noción de derecho a la movilidad, ${ }^{1}$ como lo explica Jean-Marie Duthilleul (2012):

La evolución de las ciudades debería realizarse, así, a través de un sutil equilibrio, a reajustar sin cesar, entre el movimiento y el no-movimiento, entre los lugares donde uno se queda y los lugares donde uno pasa. En cuanto este equilibrio es destruido, la ciudad no cumple más su rol de crear la relación entre la gente y lo que buscan... sin a veces saberlo. Concebir una ciudad es concebir un sistema que permite a la vez la acumulación e intercambio. La ciudad es el producto de una dialéctica permanente entre lo móvil y lo inmóvil (p.19).

De esta manera, la historia y las perspectivas de los espacios construidos en torno a esta dialéctica constituyen el objeto de esta obra, integrada por diez temas: los orígenes de la ciudad medieval (circular a pie, caballo y barco), el origen de las estaciones de trenes y la transformación de la ciudad, la irrupción de los transportes mecánicos en el siglo xIx, frente a la revolución de los transportes: las ciudades utópicas imaginadas entre 19101930, la invasión del automóvil y la transformación del espacio urbano, la creación de los aeropuertos en las inmediaciones de las ciudades, los resultados de estas transformaciones: la ciudad fragmentada (en diversos polos de actividad), las actuales transformaciones ligadas al regreso de antiguos modos de transporte (trenes ligeros, bicicletas), y finalmente las transformaciones que genera actualmente la movilidad virtual.

\section{Cuando la movilidad transforma nuestras ciudades}

El libro refiere que hace cien años los transportes motorizados irrumpieron la cotidianeidad de los habitantes de las ciudades. Desde la invención de la rueda hasta finales del siglo xIx la humanidad utilizaba tres tipos de desplazamiento: a pie, a caballo y en barco. A partir de sus necesidades, los habitantes configuraron la forma de las ciudades y sus prácticas. Las calles, puertas, plazas, puertos constituyen los espacios de circulación y los límites de la ciudad: a través de los puertos y de las puertas, los territorios lejanos entran con sus mercancías y sus alteridades.

${ }^{1}$ En 2003, el Instituto por la Ciudad en Movimiento propone el manifiesto Por la ciudad en movimiento donde figura la noción de derecho a la movilidad. 
Las calles y las plazas fueron, durante la Edad Media, el lugar de encuentro, del comercio, de la negociación, de la justicia pública.

A finales del siglo xix la revolución industrial trajo consigo la mecanización y el fin de la tracción animal y la disminución del esfuerzo humano. Las máquinas a vapor dieron origen al tren, este medio de transporte debía crearse su espacio; así, las estaciones de trenes europeas fueron construidas en las inmediaciones de las ciudades y generaron nuevos barrios y servicios. Las estaciones de trenes les gares fueron consideradas las nuevas catedrales humanas. Las nuevas puertas abiertas de las ciudades debían expresar en su majestuosa arquitectura el deseo por conocer, visitar o permanecer en los territorios lejanos y proponer el confort necesario a un nuevo valor: la velocidad.

De esta manera, rápidamente los transportes mecanizados o sin fuerza animal invadieron las calles de las ciudades sin que una rehabilitación de los espacios haya sido preparada para recibirlos. En sólo 40 años entre 1890-1930 los modos de desplazamiento se transformaron de una manera radical. No sólo con la llegada del automóvil, sino también del transporte público: el ómnibus delimitó, por primera vez, trayectos, estaciones y horarios. El metro de Londres y París se inauguró a principios del siglo xx, abriendo la posibilidad de transitar una ciudad sin poder verla de manera regular y rápida. Así también, el elevador posibilitó la construcción de las ciudades de manera vertical.

Así, el objetivo principal del desplazamiento no es sólo llegar a un lugar, sino que el traslado sea de la manera más rápida; la reducción del tiempo de desplazamiento se convierte en la búsqueda del santo grial. En efecto, el tiempo utilizado en el momento del traslado será percibido como tiempo perdido, así que entre menos dure, mucho mejor.

Durante los ańos sesenta del siglo xx, los espacios para la velocidad conquistan y transforman las ciudades. Carreteras, autopistas, estacionamientos, servicios drive, el modelo de la ciudad americana con sus interminables caminos para los automóviles se estandariza. Los transportes públicos viven un olvido. La promesa: libertad y confort serán alcanzados por cada uno de los habitantes gracias al automóvil. Así, las estaciones de trenes y las paradas de autobús se verán rápidamente abandonadas y se transformarán, como explica Marc Augé (2007), en no-lugares, en espacios anónimos con débiles características identitarias, relacionales e históricas; lugares donde el tiempo de tránsito es tiempo muerto. Las ciudades se extienden y los polos de actividad se fragmentan, las periferias se crean y el espacio urbano crece de manera tentacular. El mito del progreso-automóvil y sus infraestructuras deja un crudo sabor de boca: embotellamientos, accidentes viales, contaminación, tiempos de desplazamiento largos, ciudades dormitorio. 
Sin embargo, frente a los problemas económicos y ecológicos que provoca todo automóvil, una nueva reflexión en torno a los espacios de la movilidad se instaura. La revalorización de los modos de desplazamiento olvidados por el monopolio del automóvil y la necesidad de rehabilitación urbana para su desarrollo: el tren, la caminata, la bicicleta. Asimismo, la creación emergente de nuevos modos de utilización del automóvil, como compartir un mismo vehículo entre propietarios, entre usuarios de un servicio (car sharing, carpooling) y las energías alternativas (vehículos eléctricos, híbridos). De esta manera, redefinir los espacios de la movilidad se convierte en el nuevo desafío urbano. No se trata solamente de trabajar sobre el paisaje sino de responder a la necesidad de hacer de esos lugares espacios de vida. Evocar una potencialidad de ecosistema, re-encantar los espacios de la marcha, las estaciones de trenes, los espacios dedicados a la multimodalidad y de modos compartidos (bicicletas, automóviles). En resumen, hacer de los lugares de la movilidad, espacios donde el tiempo no es tiempo muerto, sino el espacio de nuevas prácticas sociales.

Por otra parte, la emergencia de la movilidad virtual gracias a las innovaciones tecnológicas (sistemas de navegación virtual: GPS, cartografías en línea, redes sociales, plataformas colaborativas) nos permiten realizar nuevas formas de desplazamiento que responden a la dialéctica de la movilidad-inmovilidad, es decir, uno puede ser móvil virtualmente sin tener la necesidad de realizar una movilidad física (consultar información de recursos y servicios de un territorio en línea, trabajar a distancia). Por otra parte, esta movilidad otorga a los habitantes una nueva serie de herramientas nómadas (Smartphones), que le permiten hacer de su cuerpo y su movilidad física, un cuerpo híbrido y una movilidad aumentada. De esta manera, el desafío de la movilidad urbana, no pasa solamente a través del incremento y mejoramiento de las infraestructuras necesarias para las movilidades durables (estaciones de recarga para los vehículos eléctricos, los espacios peatonales, etcétera), sino también de los servicios virtuales que pueden hacer de los modos de desplazamiento, modos más inteligentes, es decir, dar la posibilidad al usuario de adaptar su movilidad en función de sus necesidades y evitar así el incremento de las movilidades impuestas y padecidas.

\section{Bibliografía}

Marc Augé (2007), Non-lieux, introduction à une anthropologie de la surmodernité, La Librairie du xxe siècle, Seuil, Paris. 
Recibida: 11 de diciembre de 2012. Aceptada: 12 de febrero de 2013.

Elisa Mendoza-Hauchecorne Escuela de Altos Estudios en Ciencias Sociales de París

Correo-e: elisamonalisa@gmail.com

Elisa Mendoza-Hauchecorne. Es maestra en sociología por la Universidad de la Sorbona París V y la Escuela de Altos Estudios en Ciencias Sociales de París (eHess). Actualmente inscrita en la Escuela Doctoral en Ciencias Sociales de la EHess bajo la formación Territorios, Sociedades, Desarrollo. Investigadora para la consultoría francesa, especialista de las movilidades urbanas Chronos. Sus campos de investigación abordan el análisis de las movilidades urbanas, la vida cotidiana, la accesibilidad (universal design), la percepción en los espacios del transporte. Entre sus últimas publicaciones en línea destacan : "Mobilité pour tous, accessibilité pour tous", Trajectoires Fluides, Groupe Chronos, Paris, (2013); "Le vélo pour tous avec les vélos-écoles", Trajectoires Fluides, Groupe Chronos, Paris, (2012). Entre las publicaciones impresas: "Re-pensando al barrio de Tepito y la identidad nacional desde la razón sensible: una visión afectual de las identidades estigmatizadas", en Raúl Béjar, Silvano Héctor Rosales (comps.), La identidad nacional mexicana en las expresiones artisticas, unam-Plaza y Valdés, México (2009); "Momentos apocalípticos: pensamiento radical y retorno de la violencia fundadora en Michel Maffesoli", Segundo Encuentro Transdiciplinario de la Casa de México en París, Consejo Nacional para la Ciencia y la Tecnología, (2009). 